\title{
Continuous subcutaneous waking day apomorphine in the long term treatment of levodopa induced interdose dyskinesias in Parkinson's disease
}

\author{
A Colzi, K Turner, A J Lees
}

\begin{abstract}
Objectives-To determine whether continous waking day dopaminergic stimulation with the dopamine agonist apomorphine can reduce levodopa induced dyskinesias in Parkinson's disease Methods-19 patients with severe unpredictable refractory motor fluctuations and functionally disabling levodopa induced dyskinesias were treated with continuous subcutaneoius apomorphine monotherapy for a minimum duration of 2.7 years

Results-A mean $65 \%$ reduction in dyskinetic severity and a mean $85 \%$ reduction in frequency and duration occurred. On discontinuing levodopa a concomitant reduction in off period time was also seen (35\% of waking day "off" reduced to $10 \%$ ) Conclusion-Continuous waking day dopaminergic stimulation with apomorphine reset the threshold for dyskinesias and led to a pronounced reduction in their frequency. Apomorphine should be considered as a less invasive alternative to pallidotomy or deep cerebral stimulation in controlling levodopa induced interdose dose dyskinesias.

(F Neurol Neurosurg Psychiatry 1998;64:573-576)
\end{abstract}

Keywords: apomorphine; Parkinson's disease; levodopa induced dyskinesias; continuous drug delivery

Dyskinesias are a common and challenging late complication of levodopa therapy. ${ }^{1}$ Interdose dyskinesias will eventually emerge in virtually all patients and become progressively more generalised and severe. ${ }^{2}$ Although often remarkably well tolerated by patients they compromise motor capacities, may interfere with walking and balance, and lead to social embarrassment in patients and their families. Onset and end of dose (biphasic) dyskinesias occur in a proportion of younger patients and painful "off” period withdrawal dystonias are commonplace. ${ }^{3}$

The mechanisms which underlie levodopa induced interdose dyskinesias are still unclear, but even short periods of drug exposure may prime the dyskinetic response in severely disabled patients. ${ }^{4}$ Once primed, the message for the production of dyskinesias seems to be permanently stored, perhaps through some form of molecular encoding. Current concepts of the neuronal basis of dyskinesias have concen- trated on alterations in the output pathways from the striatum and stereotactic lesions placed either in the thalamus ${ }^{5}$ or in the globus pallidus ${ }^{6}$ are the most effective treatment when the abnormal movements are florid and incpacitating.

Continuous steady state dopaminerigc stimulation can greatly attenuate refractory "off" periods in patients who have become progressively disabled despite optimum adjustment of oral medication. ${ }^{78}$ Continuous intravenous or intraduodenal levodopa, although effective, is not a practical strategy for most patients because of the drug's acidity and poor solubility. ${ }^{9}{ }^{10}$ The parenterally administered dopamine agonist apomorphine has, however, proved more satisfactory and its administration by continous subcutaneous infusions using an automated syringe driver is now a widely used treatment for severe "off" period disability, in many parts of the world. ${ }^{11-13}$

Cotzias et al reported that apomorphine might have complementary properties to levodopa and suggested that it might have antidyskinetic actions when given to patients treated with levodopa. ${ }^{14}$ Some of our patients treated with apomorphine infusions also spontaneously commented that their abnormal movements were gradually lessening. In a deliberate attempt, therefore, to reduce dyskinesias induced by levodopa we embarked on a strategy to wean patients off all orally administered daytime dopaminergic drugs and treat them with a continuous subcutaneous steady state apomorphine infusion. We now report our findings in 19 patients treated for a minimum of 12 months and a mean duration of 1.9 years.

\section{Patients and methods}

In this study we have reviewed two groups of patients: In group 1 we reviewed the clincial history of 10 patients (three women, seven men) with levodopa responsive Parkinson's disease who had been treated with waking day apomorphine monotherapy for a mean duration of 4.3 (range 1.8-7.8) years. These patients received no oral antiparkinsonian drug treatment from the time when the apomorphine pump was started in the early morning to the time when the pump was removed each night before sleep. The mean age of the patients was 60.3 (range 47-70) years. The mean duration of Parkinson's disease was 18.8 (range 12-31) years. The mean duration of levodopa therapy was 18 (range 11-31) years and the median duration of apomorphine revised form 22 Octobe

1997

Accepted 23 October 1997 
Treatment data in 19 patients on waking day apomorphine monotherapy

\begin{tabular}{lcc}
\hline Treatment data & $\begin{array}{l}\text { Before apomorphine } \\
\text { monotherapy }\end{array}$ & $\begin{array}{l}\text { After 1 year of } \\
\text { apomorphine } \\
\text { monotherapy }\end{array}$ \\
\hline Mean apomorphine dose (mg/day) & $67.5(0-300)$ & $77.6(30-300)$ \\
Total levodopa dose (mg/day) & $758.5(0-2700)$ & $152.2(0-500)^{\star}$ \\
Standard levodopa & $471.7(0-1187)$ & $43.3(0-500)^{\star}$ \\
CR levodopa & $286.8(0-2700)$ & $78.9(0-500)$ \\
\hline
\end{tabular}

${ }^{\star} \mathrm{p} 0.05$, Student's $t$ test for paired data.

Values are mean (range). $\mathrm{CR}=$ controlled release

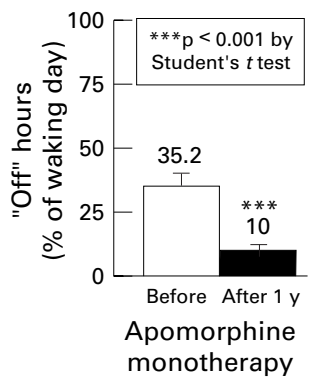

Figure 1 Off hours calculated as a percentage of waking day before (white column) and after one year of waking day

apomorphine monotherapy (black column). Absolute values are shown in each column. The bars represent the SEM of the off hours calculated as a percentage of waking day.

$\star \star \star p<0.001$ by Student's $t$ test for paired data.

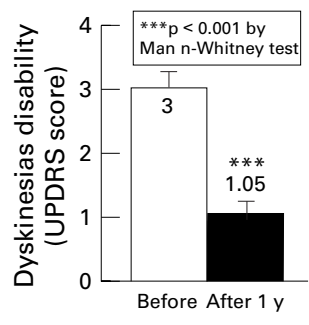

Waking day apomorphine monotherapy

Figure 2 UPDRS score for disability of dyskinesias calculated before (white column) and after one year of waking day

apomorphine monotherapy (black column). Absolute values are shown in each column. The bars represent the standard error of the mean of dyskinesias disability score. $\star \star \star$ $p<0.001$ by

Mann-Whitney test. received additional boluses throughout the therapy was 5.8 (range 3-7.75) years. One patient was receiving bromocriptine $(15 \mathrm{mg} /$ day) and benzhexol ( $4 \mathrm{mg} /$ day) and another was receiving pergolide $(1.5 \mathrm{mg} /$ day $)$. The mean daily dose of levodopa before starting apomorphine monotherapy was 620.5 (range 125-1000) mg.

In group 2 nine patients with levodopa responsive Parkinson's disease (five men, four women) who were experiencing unpredictable refractory motor fluctuations and severe levodopa induced dyskinesias were switched to continuous waking day subcutaneous apomorphine monotherapy using a Graseby MS16A or MS26 syringe driver pump. The mean age of the patients was 57.1 (range 48-74) years. The mean duration of Parkinson's disease was 15.8 (range 9-22) years. The main daily dose of levodopa was 758.85 (range 125-2700) $\mathrm{mg} /$ day and the median duration of levodopa therapy was 13.1 (range 8-22) years. Three patients were receiving pergolide $(0.75 \mathrm{mg} /$ day); one patient was treated with benzhexol (4 $\mathrm{mg} /$ day); and one patient was receiving bromocriptine ( $5 \mathrm{mg} /$ day). The mean duration of apomorphine therapy given as adjunctive treatment to oral levodopa before the start of the study in group 2 was 3 (range 1-8.5) years.

In both groups of patients levodopa was slowly but steadily reduced (on average $50 \mathrm{mg}$ a week) with a concomitant increase in apomorphine dosage if needed. The mean time needed to stabilise patients on waking day apomorphine therapy was 3.3 (range 1-6) months. Nocturnal disability in three patients continued to be treated with a single dose of controlled release levodopa and three patients also received a single early morning dose of levodopa to facilitate a kick start while waiting for the apomorphine to take effect. One patient waking day. All patients received subcutaneous apomorphine challenge tests at the beginning to confirm that they had interdose dyskinesias. Patients with biphasic dyskinesias known from previous studies not to be as effectively managed by apomorphine pump were not included.

In both groups of patients we have used self scoring diaries to assess motor fluctuations and severity and duration of dyskinesias. The UPDRS score for the disability of dyskinesias $(0=$ not disabling, $1=$ mildly disabling, $2=$ moderately disabling, $3=$ severely disabling, $4=\mathrm{com}$ pletely disabling) was also used at each outpatient visit with the patient in an "on" state and further information on duration and severity of dyskinesias was obtained from the relatives and carers of the patients, who were encouraged to accompany them at each three monthly follow up. In both groups motor disability was evaluated by calculating the total daily "off" hours expressed as a percentage of the waking day from the self scoring diaries and duration of dyskinesias was also calculated. Detailed interviews with baseline clinical data were taken during the time that they were receiving apomorphine as an "add on" treatment to oral levodopa. Data were analysed after 12 months of waking day apomorphine monotherapy in both groups and compared with baseline data.

\section{Results}

The 19 patients were treated with continuous waking day apomorphine monotherapy for a mean duration of 34.8 months (range 9 months-9 years). The group 2 patients were receiving a mean dose of 67.5 (range 0-300) $\mathrm{mg} /$ day of apomorphine before the onset of levodopa reduction and stabilised on a dose of 77.6 (range $30-300$ ) $\mathrm{mg} /$ day with waking day monotherapy (table).

Nine patients were able to stop levodopa therapy completely; four continued to take an early morning dose of standard levodopa ranging between 62.5 and $500 \mathrm{mg}$ (mean 289.5 $\mathrm{mg}$ ); another five took a nocturnal controlled release formulation at a mean dose of 400 (range 250-500) mg and one needed both early morning standard levodopa and nocturnal controlled release levodopa doses (125 mg and $250 \mathrm{mg}$ respectively), four patients continued to take the peripheral dopamine receptor antagonist domperidone in a median daily dose of 35 (range 10-60) $\mathrm{mg} / \mathrm{day}$.

The mean dose of apomorphine calculated after one year was not significantly increased (90.6 mg/day), but seven patients had a daily dose slightly higher than that before starting monotherapy. No trend for the dose of apomorphine to be continually increased was found.

A switch to apomorphine therapy led to a further significant reduction in the median daily duration of "off" time from $35.2 \%$ to $16 \%$ (fig 1). Interdose dyskinesia disability was reduced by a mean $65 \%$ and the duration of waking day dyskinesias by $85 \%$ (fig 2). Four patients who had had severe interdose dyskinesias lost their adventitious movements altogether. The time course of reduction in dyskinesia severity was variable and showed a progressive decline over several months after the patient had been established on waking day apomorphine monotherapy (mean delay to reach optimum anti dyskinetic effects after establishing apomorphine therapy was 18 weeks).

Most patients (15 of 19) experienced small abdominal cutaneous nodules at the needle site and four developed abdominal wall scarring with ulceration. It is interesting to note that some patients did not develop nodules at all even after several years of high dose apomorphine whereas others seemed to have a local hypersensitivity and developed multiple nodules within a few weeks. Aseptic needle insertion, dilution of apomorphine to $5 \mathrm{mg} / \mathrm{ml}$, 
and the regular use of abdominal ultrasound physiotherapy and silicone gel patches helped to minimise the problem.

Neuropsychiatric side effects were seen in three patients including visual hallucinations and mild confusion. Two patients developed a paranoid psychosis which was controlled by temporary short term therapy with clozapine in one, and 50-200 mg/day of sulpiride in the other; neither had to discontinue apomorphine therapy.

The analysis of clinical data carried out from the group 1 patients at the time of review-that is, after a long term apomorphine monotherapy period corresponding to to 4.5 (range $2.1-8$ ) years - did not substantially differ from that obtained after one year. Six patients had virtually continuous sustained "on" states with only an irregular and very rare return of parkinsonian disabilities for periods of less than 15 minutes at a time, and three patients developed neuropsychiatric side effects after a mean duration of treatment of 3.7 (range 3-4) years.

\section{Discussion}

Waking day levodopa must be very gradually withdrawn over several months for success to be achieved with apomorphine monotherapy. Provided this is done with encouragement and patience and a concomitant increase in apomorphine if required, most patients will experience no deterioration in motor control during the switch over phase. The present results confirm our previous studies indicating that apomorphine possesses a therapeutic potency comparable with levodopa. Complete replacement of levodopa can only be exceptionally achieved with the currently available orally active dopamine receptor agonists without a considerable deterioration in motor disabilities. This study therefore confirms previous results indicating the benefit of continuous apomorphine treatment in the management of "off" period disabilities in late stage Parkinson's disease. ${ }^{15}$

The most striking finding in our study, however, was the pronounced reduction of interdose dyskinesias without escape of motor control. The diminution occurred gradually and progressively over the first six months of monotherapy and was maintained for periods up to eight years. Six patients had a virtually continuous sustained on state with only an irregular and very rare return of parkinsonian disabilities, for less than 15 minutes at a time, and dyskinesias remained extremely mild in comparison with the preapomorphine period. However, neuropsychiatric side effects were increasingly seen with long term therapy and three patients developed troublesome hallucinations, behavioural changes, and paranoia. These results support preliminary findings from other groups, ${ }^{16}{ }^{17}$ and are in contrast with the use of intermittent subcutaneous apomorphine or apomorphine pump therapy combined with multiple daytime use of levodopa doses, when dyskinesias often get worse over time. ${ }^{18}$

Long term levodopa therapy leads to further alterations in the balance of neuronal activity in the direct and indirect striatal output pathways. For example, in the MPTP model of Parkinson's syndrome the indirect pathway is overactive, but once the animal develops dyskinesias with levodopa it becomes underactive. The direct striatal pathway which is mainly regulated by D1 dopamine receptors not only contains GABA, but colocalises the neuropeptides substantia $\mathrm{P}$ and dynorphin (tachykinins). By contrast, the indirect striopallidal pathway is mediated by D2 receptors in the striatum and has GABA and enkephalin as its chemical messengers. Alterations in activity of these pathways have recently been demonstrated by in situ hybridisation techniques measuring expression of neuropeptide mRNA. ${ }^{19}$

In MPTP treated primates a pronounced decrease in mRNA for preprotachykinin in the direct pathway and an increase in mRNA in preproenkephalin occurs in the indirect pathway. Treatment with levodopa produces a complete reversal of the preprotachykinin decrease, but seems to have no effect on the increased expression of preproenkephalin. ${ }^{20}$ These findings have also been confirmed in patients with Parkinson's disease treated with levodopa up to the time of death and in addition, diminished expression of GABA in the indirect pathway has been found. ${ }^{21}{ }^{22}$ It is clear, therefore, that levodopa therapy manipulates these D1 and D2 mediated striatal output pathways from a point of pretreatment imbalance to another different imbalance, raising the possibility that this might underlie the late development of dyskinesias. Piccini et $a l^{23}$ recently reported a PET study showing reduced putamen and thalamic opioid binding in dyskinetic, but not non-dyskinetic, patients with Parkinson's disease treated with levodopa. The ability of levodopa to alter the preprotachykinin concentrations, but not preproenkephalin concentrations, is not a property shared by all dopamine agonist drugs, however, ${ }^{24}$ and furthermore it has been shown in the 6-hydroxy-dopamine rodent model that continuous levodopa as opposed to intermittent levodopa comes closer to normalising neuropeptide expression within the striopallidal pathway. ${ }^{25}$ It is not known, however, what effect apomorphine has on these striatal output pathways, but it is possible that its effects may differ from those seen with levodopa. There are no data as yet on whether chronic, continuous apomorphine therapy can induce dyskinesias in previously untreated patients with Parkinson's disease, but the orally active ergolene dopamine agonists although clinically less potent than apomorphine, have an extremely low proclivity to induce involuntary movements. ${ }^{26}$ We are currently studying changes in opioid receptor binding in patients with Parkinson's disease and levodopa-induced dyskinesias, before and after chronic treatment with waking day apomorphine using PET.

However, it would seem more probable that apomorphine's beneficial effect in reducing dyskinesias stems from the continuous mode of administration, which may reduce erratic and intermittent striatal dopamine receptor 
changes which occur with intermittent levodopa therapy.

The pronounced reduction of motor fluctuations and dyskinesias leaves neuropsychiatric complications as the major management problem of long term apomorphine therapy. Psychotic behaviour with paranoia, hypomania, and hyperlibidinous episodes occurs in some patients, but can usually be well controlled by short term dopamine receptor blockade. There is some evidence that apomorphine has less tendency to induce neuropsychiatric problems than other dopamine receptor agonists, but nevertheless it is not free from this problem, particularly when used continuously in large doses. The abdominal nodules, although cosmetically unsightly, are generally well tolerated by patients and their families and can be helped greatly by careful skin attention supervised by a nurse-specialist. Indeed, success with the apomorphine programme depends very much on the availability of continuing advice and encouragement from Parkinson's disease nurse-specialists in addition to medical back up. In the few patients in whom nodules become a major problem intravenous administration by Portacath offers an interesting alternative. We think that the lack of demonstrable tolerance or loss of effect to apomorphine seen in our long term studies may be due to the large suprathreshold doses used in the study and the discontinuation of therapy overnight.

Our experience with apomorphine over several years consolidates the increasing evidence that continuous dopaminergic stimulation from the outset of treatment for Parkinson's disease may minimise the long term complications of motor fluctuations and dyskinesias and should continue to encourage the development of powerful, water soluble agonists which may be amenable to patch technology or new forms of drug delivery. In the meantime, apomorphine waking day monotherapy should be considered in all patients with severe levodopa induced interdose dyskinesias as a viable and less invasive approach than neurosurgical procedures such as pallidotomy and deep cerebral stimulation of the globus pallidus or subthalamic nuclei.

1 Nutt JG. Levodopa-induced dyskinesias: review, observations and speculations. Neurology 1990;40:340-5.

2 Mouradian MM, Heuser IJE, Baronti F, et al. Pathogenesis of dyskinesias in Parkinson's disease. Ann Neurol 1989;25 523-6.
3 Lees AJ. L-dopa treatment and Parkinson's disease. $Q 7 M e d$ 1986;59:534-7.

4 Lang AE, Meadows JC, Parkes JD, et al. Early onset of the on-off phenomenon in children with symptomatic parkinsonism. F Neurol Neurosurg Psychiatry 1982;45:823-5.

5 Narabayashi H, Yokachi F, Nakajima Y. Levodopa-induced dyskinesias and thalamotomy. $\mathcal{F}$ Neurol Neurosurg Psychiatry 1994;47:831-9.

6 Dogali M, Cazzini E, Kolodny E, et al. Stereotactic ventral pallidotomy for Parkinson's disease. Neurology 1995;45: $753-61$

7 Obeso JA, Luquin MR, Martinez-Lage JM. Lisuride infusion pump: a device for the treatment of motor fluctuations in Parkinson's disease. Lancet 1986;i:467-70.

8 Stibe CMH, Kempster PA, Lees AJ, et al. Subcutaneous apomorphine in parkinsonian on-off oscillations. Lancet 988;i:403-6.

9 Sage JI, Mark MJ. The rationale for continuous dopaminergic stimulation in patients with Parkinson's disease. Neurology 1992;42(suppl 1):23-8.

10 Quinn N, Parkes JD, Marsden CD. Control of on/off phenomenon by continuous intravenous infusion of phenomenon by continuous intraver

11 Pollak P, Champay AS, Hommel M, et al. Subcutaneous apomorphine in Parkinson's disease. $f$ Neurol Neurosurg Psychiatry 1989;52:544.

12 Poewe W, Kleedorfer B, Wagner $\mathrm{M}$, et al. Continuous apomorphine in the treatment of Parkinson's disease. $A d v$ Neurol 1993;60:656-9.

13 Frankel JP, Lees AJ, Kempster PA, et al. Subcutaneous apomorphine in the treatment of Parkinson's disease. F Neurol Neurosurg Psychiatry 1990;53:96-101.

14 Duby SE, Cotzias GC, Papavasiliou PS, et al. Injected apomorphine and orally administered levodopa in parkinsonism. Arch Neurol 1972;27:474-80.

15 Hughes AJ, Bishop S, Kleedorfer B, et al. Subcutaneous apomorphine in Parkinson's disease: response to chronic treatment for up to five years. Mov Disord 1993;8:165-70.

16 Cotzias GC, Mena I, Papavasiliou PS, et al. Unexpected findings with apomorphine and their possible consequences. Adv Neurol 1974;5:295-9.

17 Chaudhuri RK, Critchley P, Abbott RJ, et al. Subcutaneous apomorphine for on'off oscillations in Parkinson's disease. Lancet 1988;ii: 1260.

18 Steiger MJ, Quinn NP, Marsden CD. The clinical use of apomorphine in Parkinson's disease. F Neurol 1992;239: 389-93.

19 Albin RL, Young AB, Penney JB. The functional anatomy of the basal ganglia disorders. Trends Neurosci 1989;12:36674.

20 Herroro M, Augood SJ, Hirsch EC, et al. Effect of L-dopa on pre-proenkephalin and pre-protachykinin gene expression in the MPTP-treated monkey striatum. Neuroscience 1995;68:1189-98.

21 Nisbet AP, Foster OJ, Kingsbury A, et al. Pre-proenkephalin and pre-protachykinin mRNA expression in normal human basal ganglia and in Parkinson's disease. Neuroscience 1995; 66:361-76.

22 Nisbet AP, Eve DJ, Kingsbury A, et al. Glutamate decarboxylase-67 messenger RNA expression in normal human basal ganglia and in Parkinson's disease. Neuroscience 1996;75:389-406.

23 Piccini P, Wilks RA, Burn DJ, et al. PET studies on opioid receptor binding in Parkinson's disease patients with and without levodopa-induced dyskinesias [abstract]. Neurology 1995;46(suppl 2):S6-12.

24 Jenner $P$. The rationale for the use of dopamine agonists in Parkinson's disease. Neurology 1995;45 (suppl 3):S6-12

25 Engber TM, Suzel Z, Juncos JL, et al. Continuous and intermittent levodopa differentially affect rotation induced by D1 and D2 dopamine agonists. Eur 7 Pharmacol 1989;168:291-8.

26 Lees AJ, Stern GM. Sustained bromocriptine therapy in previously untreated patients with Parkinson's disease. $\mathcal{F}$ Neurol Neurosurg Psychiatry 1981;44:1020-3. 